\title{
WATER HEATING WITH TRACKING TO SUN SOLAR BATTERIES
}

\author{
Ilze Pelece, Henriks Putans, Imants Ziemelis, Liene Kancevica \\ Latvia University of Agriculture \\ ilze.pelece@1lu.lv, henriksooo@inbox.lv,imants.ziemelis@1lu.lv, liene.kancevica@1lu.lv
}

\begin{abstract}
Traditionally it has been considered that solar collectors are more effective for water heating than solar batteries (PV) because of changing of energy from heat to electricity and then back to heat in the case of batteries. But there are some aspects why solar batteries can be more effective for water heating than solar collectors, especially in northern countries, where ambient temperature is low. The first of them is negative impact of temperature difference between the absorber of the solar collector and ambient air on the efficiency of the solar collector. Therefore, efficiency of the solar collector importantly decreases with increasing of the temperature of the obtained hot water. The efficiency of solar batteries only slightly depends on temperature and, opposite to the case of solar collectors, is higher at lower ambient temperature. The same situation is at the heat exchanger traditionally used with the solar collector: the amount of heat given from the heat carrier to usable water depends on the temperature difference between them. Electricity from solar batteries heats water independently on its temperature. Also tracking to sun is more complicated for solar collectors than for solar batteries. Water heating using tracking to sun solar batteries has been studied in this work. Two photovoltaic panels Solet P6.60-WF-250 with surface area $3.25 \mathrm{~m}^{2}$ each, mounted on a dual axis tracking device, were used for water heating with electrical resistance heaters. Measurements were carried out from 1 of August till 22 of October 2016. The results show that the measured power of batteries on sunny October day is approximately $500 \mathrm{~W}$ and 281 reservoir without heat insulation of water has been heated up to $50 \ldots 70{ }^{\circ} \mathrm{C}$, or by $30^{\circ} \mathrm{C}$ during $2 \mathrm{~h}$ what corresponds to $490 \mathrm{~W}$ received power. An opposite dependence of the photovoltaic efficiency on ambient temperature also has been observed.
\end{abstract}

Keywords: solar energy, solar batteries, tracking to sun, water heating.

\section{Introduction}

Solar collectors are used mainly for water heating. Only one study [1] has been found where photovoltaic are used together with the conventional heating system. It can be explained by particularities in use of solar radiation in different latitudes. The main solar energy using countries are in low latitudes: the leading countries are China, Turkey, Brazil and India [2]. Therefore, also almost all studies in this branch are concentrated in these countries, only one article [3] from several hundred has been found related to use of solar energy in latitudes higher than $50^{\circ}$. In northern countries, for example in Latvia, solar energy has been used [4], but mainly in the same kinds as in the southern ones without taking into account the particularities of use of solar energy in higher latitudes. Among other peculiarities [5], in this case the most important role is played by lower ambient temperature.

Although efficiency of photovoltaic is only about 0.2 (or even 0.15 for large-scale production), but of solar collectors it is up to 0.75 (or approximately 0.5 for large-scale production), there only the same device has been taken into account. For solar collectors heat losses take place also in one or two (depending on construction) heat exchangers, where more effective heat transfer is possible if temperature of heat carrying fluid is high, and in the transferring process from the place of producing to the place of consuming (especially, if the distance is long and/or the temperature of ambient air is low), where losses are directly proportional to the temperature of the heated water. For photovoltaic transferring of the energy from the place of production to the place of consuming goes on as electricity by wires almost without losses independently on distance. Also converting of electrical energy to heat is carried out almost without losses, only at high temperatures some decreasing of the efficiency can occur due to the dependence of the resistance of the heater on temperature.

Unfavourable impact of high ambient temperature on the efficiency of photovoltaic also must be taken into account.

\section{Materials and methods}

Two solar panels (PV) Solet P60.6- WF-250 with the nominal power $250 \mathrm{~W}$ and the surface area $3.25 \mathrm{~m}^{2}$ for each were used for water heating. Solar panels were mounted on the tracking to sun system ST44M2V4P (Fig. 1). Water was heated in a plastic container (volume of the container 301 , 
amount of water 28 1) without thermal insulation, so heat losses from the container imitate consuming hot water. Two electrical heaters with electrical resistance $21 \Omega$ each connected in parallel were used.

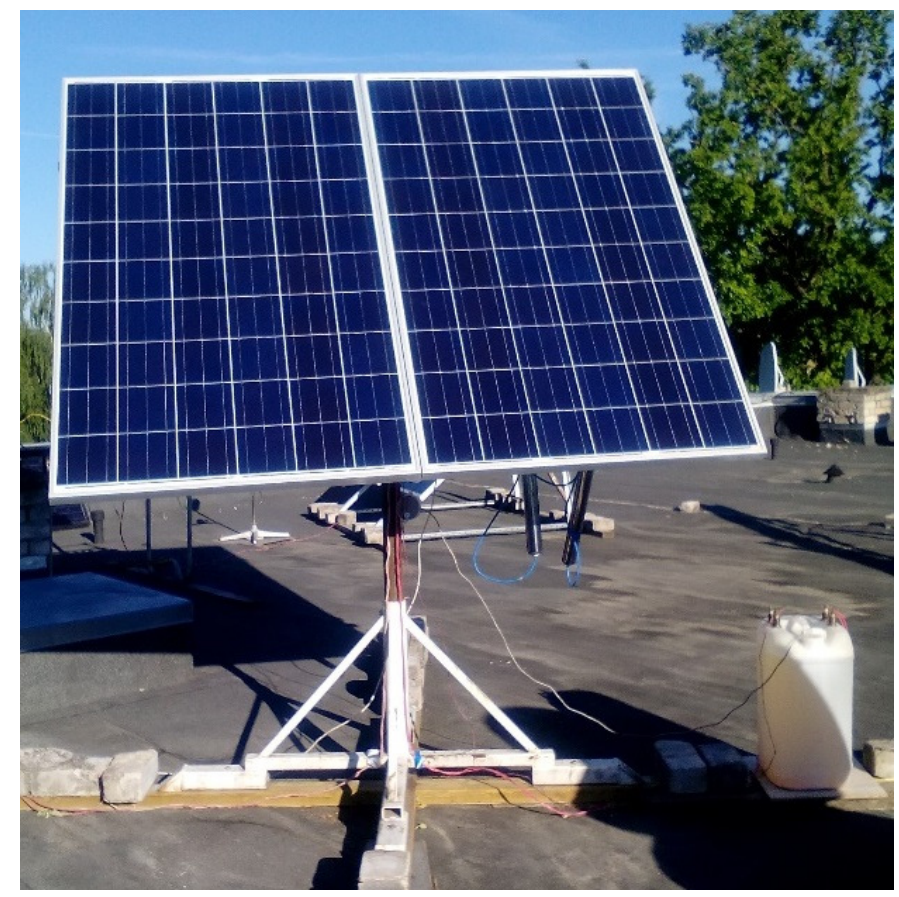

Fig. 1. Tracking device with two solar panels and water container

The technical scheme of the experimental device is shown in Fig. 2. Data loggers HOBO were used to register the voltage of the solar panels as well as temperatures of water and ambient air. Measurements after every 5 min were taken.

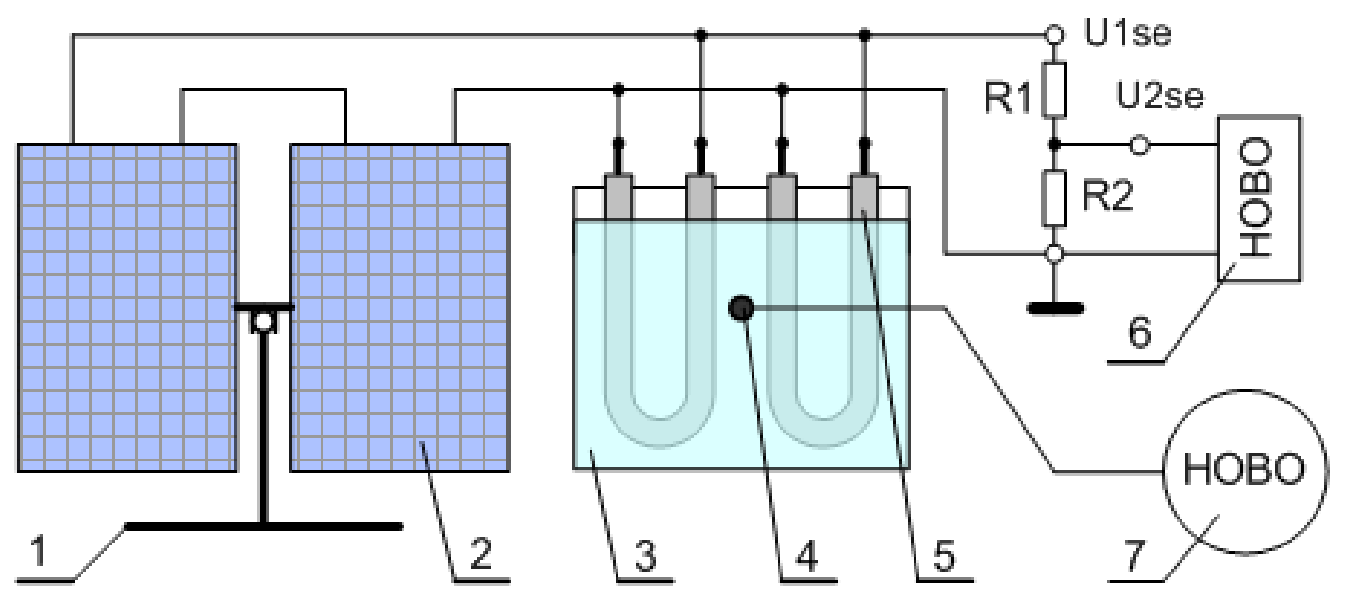

Fig. 2. Technical scheme of experimental device: 1 - solar tracker; 2 - solar panels; 3 - water container; 4 - temperature sensor; 5 - heater; 6, 7 - data loggers

Measurements have been carried out from August 1 till October 22, 2016.

Power of the solar panels can be calculated as:

$$
P=U \cdot \frac{1}{4} R^{2},
$$

where $P$ - power of panel, $\mathrm{W}$;

$U$ - measured voltage, $\mathrm{V}$;

$R$ - resistance of one heater, $\Omega$.

At higher temperatures dependence of electrical resistance of the heater on temperature can affect the heating power: 


$$
R=R_{0}(1+\beta t),
$$

where $R$ - resistance at temperature $t, \Omega$;

$R_{0}$ - resistance at zero temperature, $\Omega$;

$\beta$ - thermal coefficient of resistance, $\mathrm{K}^{-1}$;

$t$ - temperature, ${ }^{\circ} \mathrm{C}$.

In our case the temperatures were not higher $70{ }^{\circ} \mathrm{C}$, therefore this impact did not exceed $2 \%$ if $\beta=4 \cdot 10^{-4} \mathrm{~K}^{-1}$ and can be neglected.

Power received by water has been calculated as

$$
P_{1}=c \cdot m \cdot \Delta T,
$$

where $P_{1}$ - heating power, $\mathrm{W}$;

$c$ - specific heat of water, $\mathrm{J} \cdot(\mathrm{kg} \cdot \mathrm{K})^{-1}$;

$m$ - mass of heated water, $\mathrm{kg}$.

Heat losses from the container can be calculated using Newton's cooling law

$$
P_{2}=\propto\left(T-T_{0}\right) \cdot S,
$$

where $P_{2}$ - power losses, W;

$\alpha$ - heat transfer coefficient, $\mathrm{W} \cdot\left(\mathrm{K} \cdot \mathrm{m}^{2}\right)^{-1}$;

$T$ - temperature of hot water, $\mathrm{K}$;

$T_{0}$ - ambient temperature, $\mathrm{K}$;

$S$ - surface of container, $\mathrm{m}^{2}$.

The heat transfer coefficient $\alpha$ takes into account both convection and radiation and can be evaluated from cooling of the container at night.

\section{Results and discussion}

Fig. 3 shows the day course of the power produced by the solar panels together with that of the solar power density on the surface perpendicular to the sun rays.

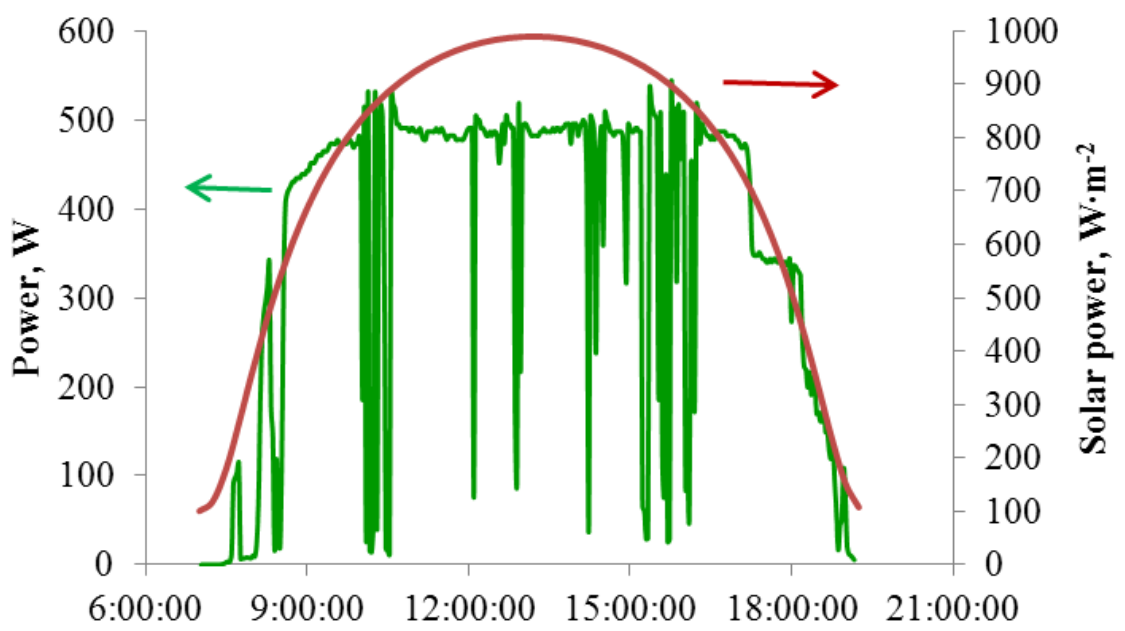

Time

Fig. 3. Day course of power produced by panels (green line) and solar irradiance (red line) on September 162016

It can be seen that power of the panels reaches nominal (producer specified) value of $500 \mathrm{~W}$ at solar irradiance approximately $600 \mathrm{~W} \cdot \mathrm{m}^{-2}$, giving efficiency approximately $13 \%$ (instead of the producer specified $15 \%$ ) and does not increase at higher values of solar irradiance, what means decreasing of the efficiency to $7 \%$ at midday. It means that such solar panel is more effective in northern countries where solar irradiance is less. 
The characteristic day course of temperature of the heated water together with that of the power produced by the panel is shown in Fig.4.

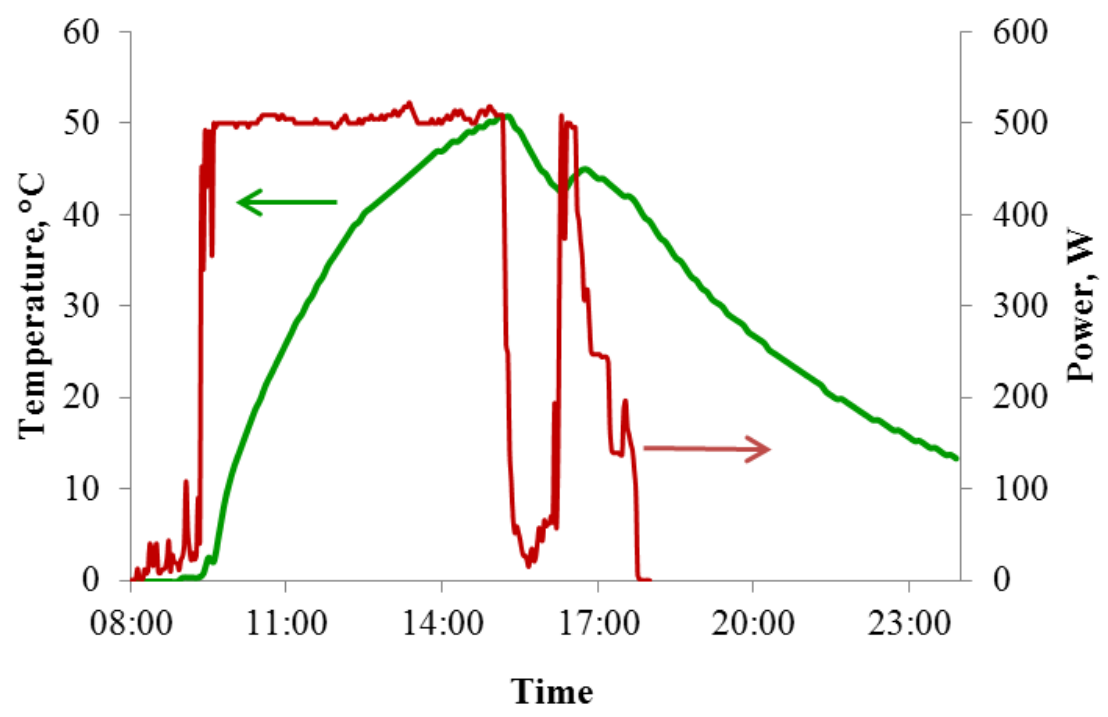

Fig. 4. Day course of temperature of heated water (green line) and power produced by solar panels (red line) on October 132016

Approximately till 15:00 the day was sunny, the solar panels produced nominal power $500 \mathrm{~W}$ and water temperature rose fast at the beginning then slower due to increasing of heat losses proportionally to the difference of temperatures between hot water and ambient air, and also temperature equalization in the container plays a role. After 18:00 the sun set and water started to cool down. From cooling the heat loss coefficient (including radiation and convection) has been evaluated equal to 6.2 using formula (4).

Heated water and ambient air temperatures during all August are shown in Fig. 5.

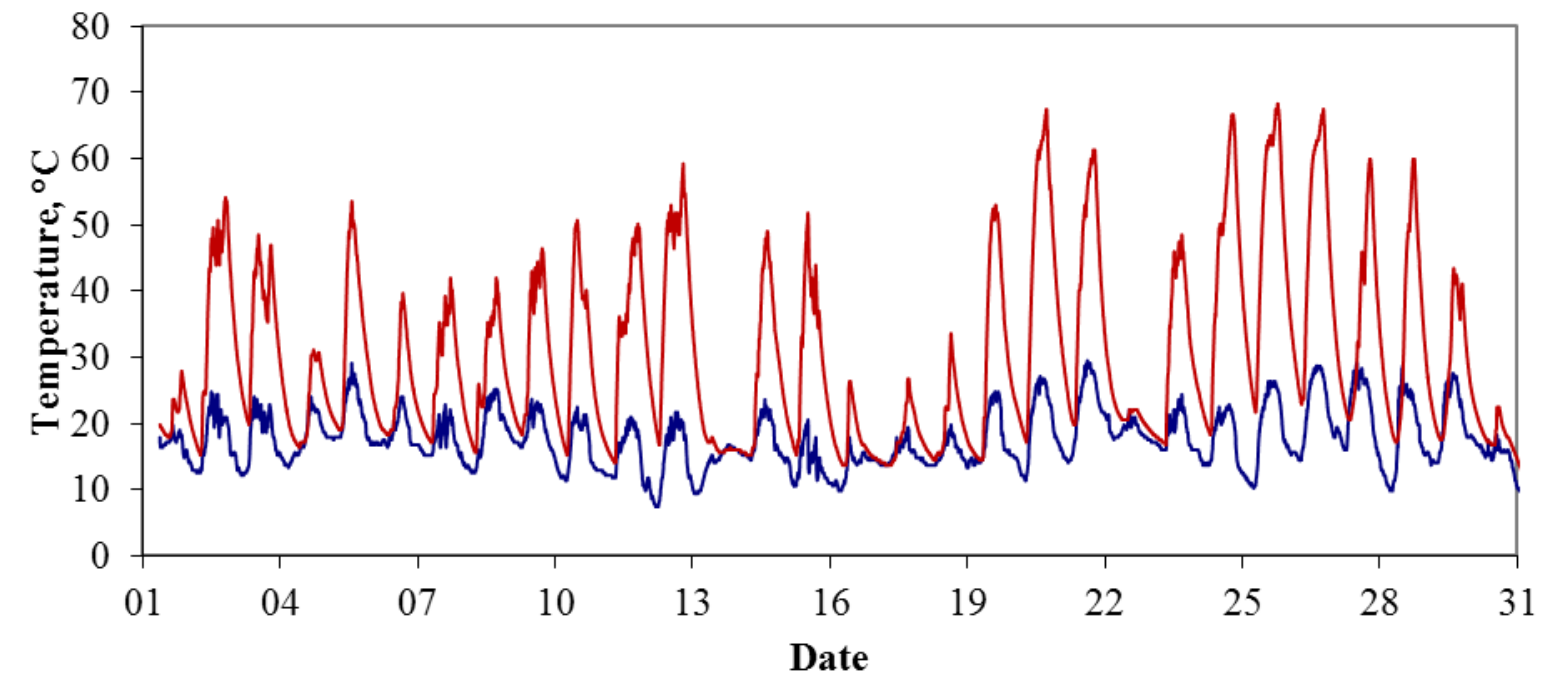

Fig. 5. Temperatures of heated water (red line) and ambient air (blue line) in August 2016

The energy amount received by water cannot be calculated correctly from these measurements because of uneven warming of water in the container due to convectional stratification. Therefore, the maximal temperature of water was considered as a better value characterising the heating process. It can be assumed that at the moment of the maximal temperature (usually at midday) the temperature of water is even in all volume of the container.

Fig. 6 shows the dependence of daily maximal temperature of water on daily maximal power produced by the solar panels. 


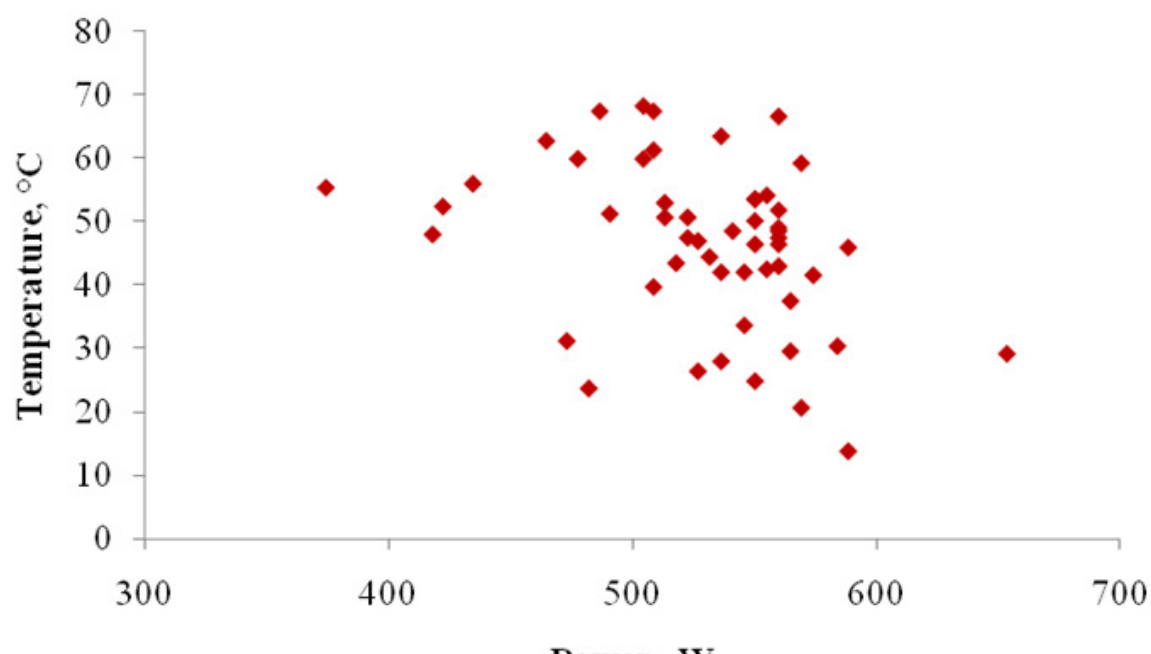

Power, W

Fig. 6. Dependence of daily maximal temperature of heated water on daily maximal power produced by solar panels

Unexpectedly, it seems that the dependence is reversed - higher power produces not so hot water. It can be explained by the dependence of the power of solar panels on ambient temperature, discussed further (Fig. 8). Dependence of water maximal temperature on the maximal power of solar panels is too weak $\left(R^{2}=0.13\right)$ to be analyzed in more detail. More detailed investigations should be done to obtain stronger correlation.

Fig. 7 shows the dependence of water maximal temperature on ambient air temperature.

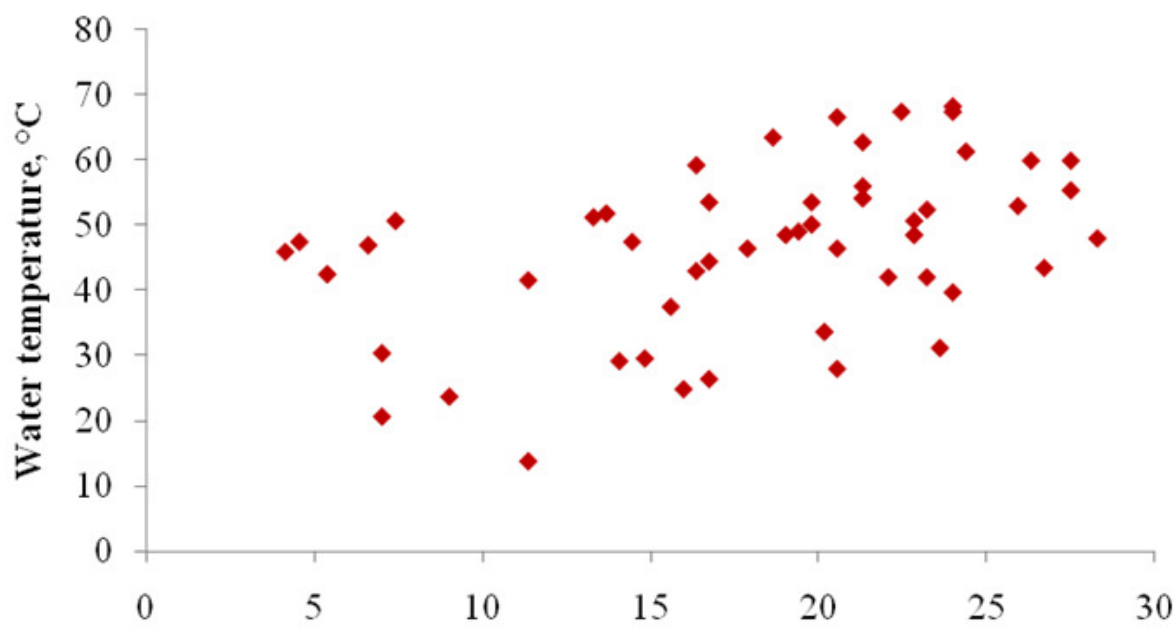

Ambient temperature, ${ }^{\circ} \mathrm{C}$

Fig. 7. Dependence of water maximal temperature on ambient air temperature

This dependence is a little stronger, but also weak $\left(R^{2}=0.19\right)$. Such dependence can be explained by higher ambient temperature on sunny days. The impact of higher ambient temperature on heat losses is small in this case, but also can affect this dependence.

Dependence of maximal power on ambient temperature has been observed and displayed in Fig.8. Power of solar panels increases at lower ambient temperatures. Such dependence corresponds to that mentioned in many literature sources, for example, [6]. Also the producer of the solar panels specified such dependence. Although the dependence is not strong $\left(R^{2}=0.18\right)$, the difference in power is noteworthy.

The producer has specified that the thermal coefficient of power is $-0.47 \% \cdot \mathrm{K}^{-1}$. We obtained $-0.53 \% \cdot \mathrm{K}^{-1}$, but the maximal power of the panels is more than specified, it reaches $600 \mathrm{~W}$. It also means that such panel is more effective in northern countries, where the ambient temperature is lower. 


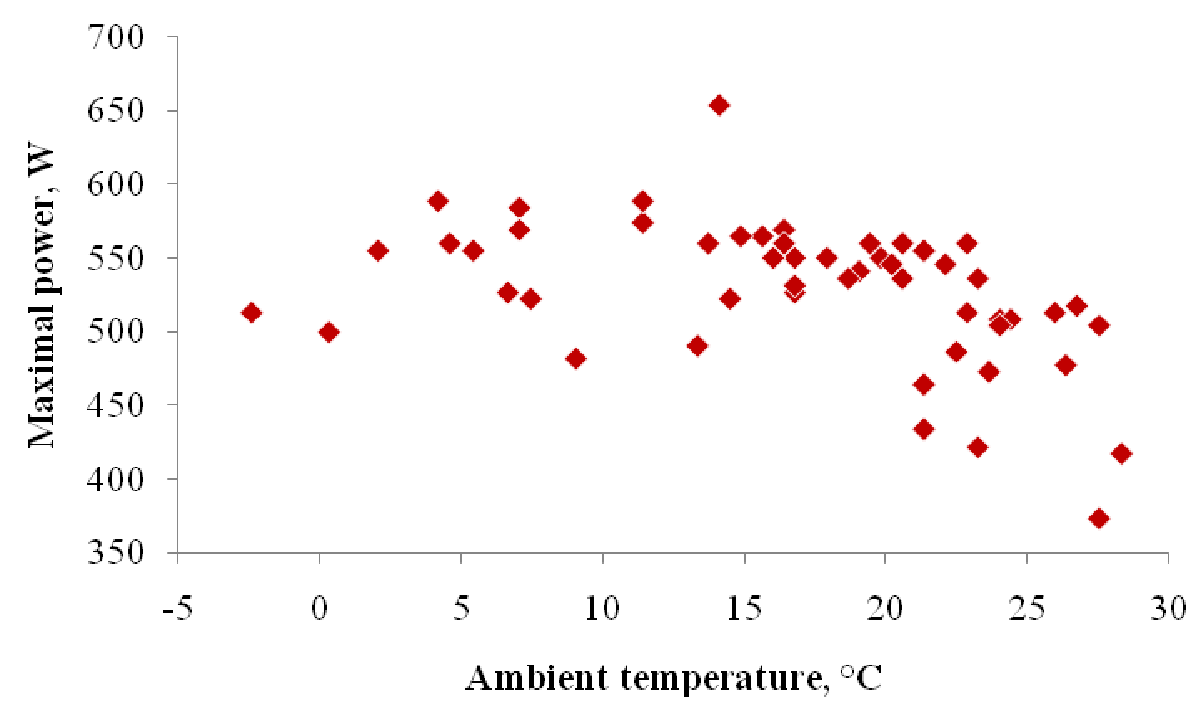

Fig. 8. Dependence of maximal power of panels on ambient temperature

\section{Conclusions}

1. Solar panels can be used for water heating with electricity.

2. Advantages of water heating with solar panels instead of solar collectors are less thermal losses in all parts of the system.

3. These advantages are more pronounced in northern countries.

4. The solar panels used in this experiment are more appropriate for use in northern countries because of the dependence of the power on ambient air temperature specified by producer, and small (if any) increase of the power at higher solar irradiance.

\section{References}

1. Beccali M., Cellura M., Longo S., Guarino F. Solar heating and cooling systems versus conventional systems assisted by photovoltaic: Application of a simplified LCA tool. Solar Energy Materials \& Solar Cells 156(2016), pp. 92-100.

2. Gautam A., Chamoli S., Kumar A., Singh S. A review on technical improvements, economic feasibility and world scenario of solar water heating system. Renewable and Sustainable Energy Reviews 68 (2017), pp. 541-562.

3. Brown C., Perisoglou E., Hall R., Stevenson V. Transpired solar collector installations in Wales and England. Energy Procedia 48 (2014), pp. 18-27.

4. Shipkovs P., Kashkarova G., Lebedeva K., Migla L., Snegirjovs A., Shipkovs, J. Potential and analysis of grid integrated renewables in Latvia (Conference Paper). ISES Solar World Congress, SWC 2013; Cancun; Mexico; 3 November 2013 through 7 November 2013; Code 110444. Energy Procedia Volume 57, 2014, pp. 735-744.

5. Pelece I., Shipkovs P. Theoretical and experimental investigations of cylindrical air-heating solar collector. Latvian Journal of Physics and Technical Sciences, Volume 53, Issue 3, 1 June 2016, pp. 11-21.

6. Kumar R., Rosen M. A. A critical review of photovoltaic-thermal solar collectors for air heating. Applied Energy 88 (2011), pp. 3603-3614. 